\title{
Proliferation-rate Effects of BAP and Kinetin on Banana (Musa spp. AAA Group) 'Basrai'
}

\author{
Aish Muhammad ${ }^{1}$, Hamid Rashid, and Iqbal Hussain \\ Agriculture Biotechnology Programme, National Agriculture Research \\ Centre, Park Road, Islamabad 45500, Pakistan
}

\section{S.M. Saqlan Naqvi \\ Department of Biochemistry, University of Arid Agriculture Rawalpindi, Muree Road, Rawalpindi 46000, Pakistan}

Additional index words. shoot tip, in vitro multiplication, micropropagation, cytokinin

\begin{abstract}
The effect of benzylaminopurine (BAP) and kinetin alone and in combination with indole 3-acetic acid (IAA) on shoot proliferation of 'Basrai' (Musa spp., AAA group) was investigated. Shoot tips $(4-6 \mathrm{~mm})$ were excised from field-grown suckers to initiate the cultures. Concentrations of BAP and kinetin ranged from 0.0 to $8.0 \mathrm{mg} \cdot \mathrm{L}^{-1}$ each on solid or in liquid MS medium. When liquid medium was used, cultures were agitated continuously on an orbital shaker moving at $40 \mathrm{rpm}$. Three subculture regimes were employed; after each subculture, the number of shoots regenerated from each explant was counted. The results showed that the multiplication rate was significantly $(P \leq 0.05)$ dependent upon cytokinin type, its concentration, and type of medium used. The maximum number of shoots regenerated from a single shoot tip was achieved in liquid MS medium containing $4.0 \mathrm{mg} \cdot \mathrm{L}^{-1}$ BAP. There was no significant difference between liquid and solid medium when kinetin was used; however, kinetin at $4.0 \mathrm{mg} \cdot \mathrm{L}^{-1}$ or above yielded significant results as compared with the control and lower kinetin concentrations. The results demonstrated that $4.0 \mathrm{mg} \cdot \mathrm{L}^{-1} \mathrm{BAP}$ with $1.0 \mathrm{mg} \cdot \mathrm{L}^{-1} \mathrm{IAA}$ in liquid medium was best for shoot multiplication and shoot height during micropropagation of 'Basrai'.
\end{abstract}

Banana is cultivated over an area of 29,700 ha with annual production of $142,900 \mathrm{t}$ in Pakistan (GOP, 2004-2005). 'Dwarf Cavendish' is cultivated on $98 \%$ of the area under banana cultivation in Pakistan. This crop was introduced from Bombay (India) to Sindh province in 1937 , but its commercial cultivation started in 1947. Per-hectare income from banana was higher as compared with other crops, like wheat (Triticum aestivum L.) and sugarcane (Saccharum officinarum L.). Therefore, the farmers started banana cultivation, and in a short period, a large area along the left bank of the Indus River went under banana cultivation.

During the early 1990s, banana bunchy top disease (BBTD) was identified in bananagrowing areas of Pakistan (Soomro et al., 1992). The casual agent of this disease was banana bunchy top virus (BBTV). As banana is vegetatively propagated, BBTV spreads to new fields with planting material. Black aphid (Pentalonia nigronervosa) is also present in the area, which is a vector for BBTV. Moreover, strong winds blowing from south to northwest also help to move the black

\footnotetext{
Received for publication 9 Jan. 2007. Accepted for publication 24 Feb. 2007.

The Pakistan Science Foundation (PSF) is acknowledged for their funding of this research project (Biotech/36).

${ }^{1}$ To whom reprint requests should be addressed; email aish_muhammad@yahoo.com
}

aphid and increase the distribution of the virus. Due to BBTD, per-hectare yield decreased drastically.

The future of banana industry in the country is totally dependent upon control of this disease. The ultimate choice is production of disease-free banana plants through in vitro techniques to replace infected fields. In this study, various concentrations of BAP and kinetin were exploited to achieve higher rates of multiplication of 'Basrai'. Moreover, the effect of liquid and solid media on the multiplication rate was studied.

\section{Materials and Methods}

Cultures were started from 4-week-old field-grown sword suckers of 'Basrai'. These suckers were collected from fruiting mother plants, and at the time of separation, these were $\approx 30 \mathrm{~cm}$ in height and looking healthy. In the laboratory, outer leaves were peeled off until the explants were $3 \mathrm{~cm}$ in height and $1 \mathrm{~cm}$ at the base. These explants were surface-sterilized with $2.75 \%$ sodium hypochlorite (Clorox, Oakland, CA) for $10 \mathrm{~min}$. A few drops of Tween-20 were added during sterilization, and explants were shaken continuously for uniform sterilization. After the explants were washed with sterile distilled water, further trimming was carried out under an aseptic environment (in a laminar flow hood) to the required size $(4-6 \mathrm{~mm})$.

For culture initiation, MS medium (Murashige and Skoog, 1962) was used with
$2.0 \mathrm{mg} \cdot \mathrm{L}^{-1} \mathrm{BAP}$ and $0.1 \mathrm{mg} \cdot \mathrm{L}^{-1} \mathrm{IAA}$. Medium was solidified with $2 \mathrm{~g} \cdot \mathrm{L}^{-1}$ Gelrite (Sigma Chemical Co., St. Louis), and its $\mathrm{pH}$ was adjusted to 5.7 before autoclaving. Media were dispensed in $250-\mathrm{mL}$ conical flasks, which were plugged with cotton and autoclaved at $121^{\circ} \mathrm{C}$ for $15 \mathrm{~min}$. Explants were cultured on the medium in such a way that the explant's rhizome was embedded in the medium. After the start of the growth of the explants, external leaves were collected for ELISA testing. An ELISA kit (Sanofi Pasteur Diagnostics [Phyto], Marnes-La-Coquette, France) was used for BBTV detection. A double-antibody sandwich (DAS) ELISA was performed according to the manufacturer's instructions. Samples that had an absorbance value at $A_{405 \mathrm{~nm}}$ double that of a negative control were evaluated as "positive."

Virus-free explants were transferred onto multiplication medium. After initiation, explants were transferred on various multiplication media in a completely randomized pattern, and six cultures were transferred on each treatment. Multiplication medium was MS with BAP or kinetin at $1,2,4,6$, or $8 \mathrm{mg} \cdot \mathrm{L}^{-1}$ each with 1.0 or $2.0 \mathrm{mg} \cdot \mathrm{L}^{-1}$ IAA. MS medium without hormones was used as control. For shoot multiplication, liquid and solid media were used and cultures were shaken continuously at $40 \mathrm{rpm}$ during liquid culture. Subculturing was done after every 4 weeks on the same medium. Black parts in the culture were removed before subculturing. Multiplication was carried out up to the third subculture to evaluate the type of cytokinin, its concentration, and type of medium (liquid or solid) used. The multiplication rate was calculated as the ratio of shoot number at the end of subculture to the initial number of shoots. After multiplication, the individual shoots were separated from the bunch and transferred to rooting medium.

\section{Results and Discussion}

In the absence of plant growth hormones, each shoot tip grew into single shoot (Fig. 1A). When cytokinins were added to the medium, swelling was observed at the base of explants (Fig. 1B). Addition of auxin had no additional effect on proliferation (data not shown). At lower concentrations of cytokinin, lateral buds from the base of the leaves grew into individual shoots (Fig. 1C); however, increasing cytokinin concentration to $6 \mathrm{mg}$ resulted in adventitious shoot proliferation (Fig. 1D). Further increases in cytokinin concentration to $8.0 \mathrm{mg} \cdot \mathrm{L}^{-1}$, resulted in a decreased proliferation rate, indicating an adverse effect of plant growth regulators beyond the optimal dose (Table 1).

Results of shoot multiplication at various concentrations of BAP showed that, when on control medium, the number of shoots/ explant was 1.3 (Table 1). With increases in BAP concentration, numbers of shoots/ explant increased and a maximum of 5.4 shoots/explant was achieved when the liquid medium contained $4.0 \mathrm{mg} \cdot \mathrm{L}^{-1}$ BAP (Table 1 ). 

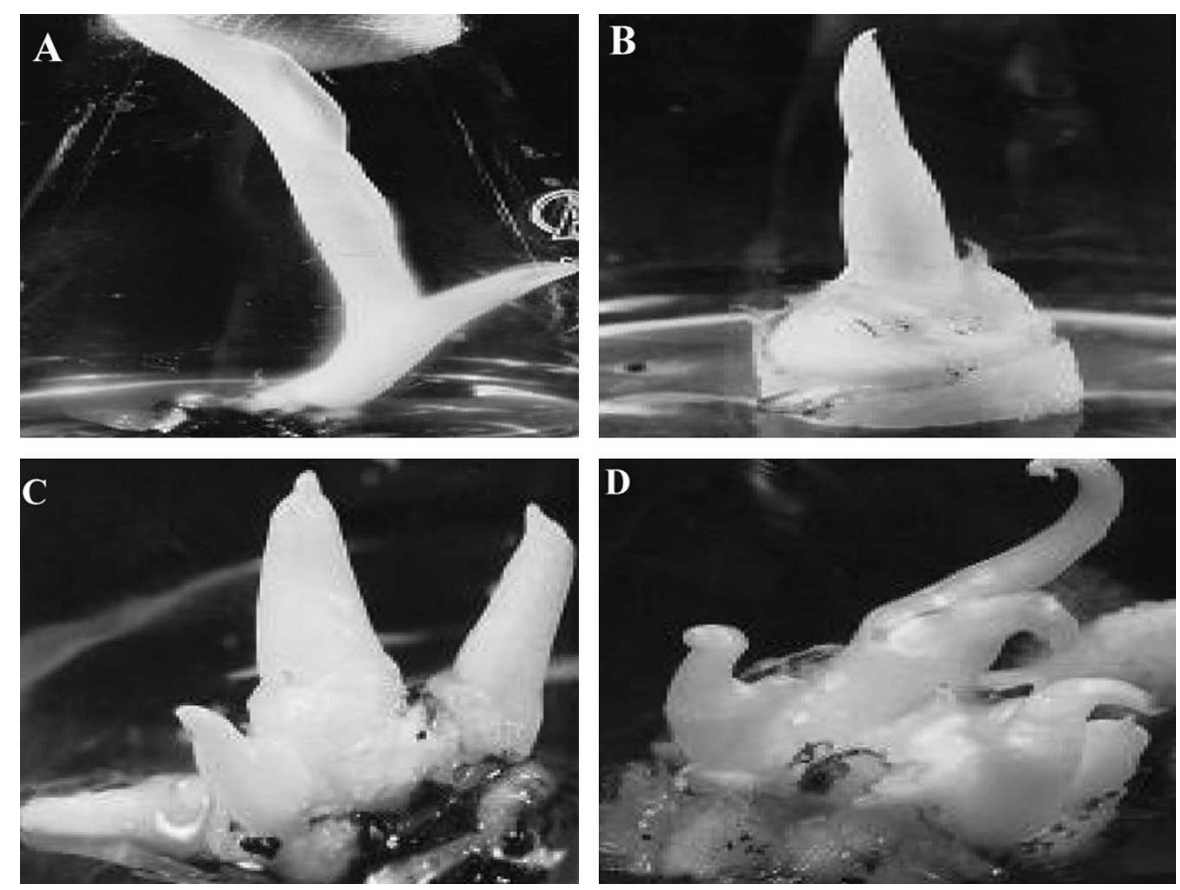

Fig. 1. Shoot proliferation patterns of banana with various cytokinin concentrations: (A) without cytokinin (B) swelling of tissues when cytokinin was added; (C) lateral buds originating at lower concentrations; and (D) adventitious bud formation at higher cytokinin concentrations.

Table 1. Effect of different concentrations of BAP and kinetin on shoot multiplication of banana 'Basrai' in liquid and solid culture media after three subculturings. ${ }^{\mathrm{z}}$

\begin{tabular}{|c|c|c|c|c|}
\hline \multirow{2}{*}{$\begin{array}{l}\text { Concn of BAP or } \\
\text { kinetin }\left(\mathrm{mg} \cdot \mathrm{L}^{-1}\right)\end{array}$} & \multicolumn{2}{|c|}{$\begin{array}{l}\text { Number of shoots/explant } \\
\text { on medium with BAP }\end{array}$} & \multicolumn{2}{|c|}{$\begin{array}{l}\text { Number of shoots/explant } \\
\text { on medium with kinetin }\end{array}$} \\
\hline & Liquid medium & $\overline{\text { Solid medium }}$ & Liquid medium & $\overline{\text { Solid medium }}$ \\
\hline$\overline{0.0}$ & $1.3 \pm 0.05 \mathrm{e}$ & $1.4 \pm 0.05 \mathrm{e}$ & $1.3 \pm 0.09 \mathrm{~b}$ & $1.3 \mathrm{~b}$ \\
\hline 1.0 & $1.6 \pm 0.2 \mathrm{e}$ & $1.6 \pm 0.05 \mathrm{e}$ & $1.4 \pm 0.05 \mathrm{~b}$ & $1.4 \pm 0.05 \mathrm{~b}$ \\
\hline 2.0 & $4.2 \pm 0.34 \mathrm{bc}$ & $2.9 \pm 0.05 \mathrm{~d}$ & $2.0 \pm 0.19 \mathrm{~b}$ & $1.8 \pm 0.14 \mathrm{~b}$ \\
\hline 4.0 & $5.4 \pm 0.33 \mathrm{a}$ & $3.4 \pm 0.14 \mathrm{~cd}$ & $4.3 \pm 0.11 \mathrm{a}$ & $4.1 \pm 0.48 \mathrm{a}$ \\
\hline 6.0 & $5.4 \pm 0.33 \mathrm{a}$ & $4.8 \pm 0.16 \mathrm{ab}$ & $4.7 \pm 0.24 \mathrm{a}$ & $4.4 \pm 0.16 \mathrm{a}$ \\
\hline 8.0 & $5.1 \pm 0.31 \mathrm{ab}$ & $4.4 \pm 0.11 \mathrm{bc}$ & $4.1 \pm 0.20 \mathrm{~b}$ & $4.5 \pm 0.04 \mathrm{a}$ \\
\hline
\end{tabular}

${ }^{\mathrm{z}}$ Values having the same letters are nonsignificant at $P \leq 0.05$.

Table 2. Analysis of variance (ANOVA) for shoot multiplication on MS medium (solid or liquid) with different concentrations of BAP, kinetin, and IAA.

\begin{tabular}{|c|c|c|c|c|}
\hline \multirow[b]{2}{*}{ Serial number } & \multirow[b]{2}{*}{$\begin{array}{l}\text { Source of } \\
\text { variation }\end{array}$} & \multirow[b]{2}{*}{$\begin{array}{l}\text { Degrees of } \\
\text { freedom }\end{array}$} & \multicolumn{2}{|c|}{ Mean square } \\
\hline & & & $\begin{array}{c}\text { No. of shoots } \\
\text { on BAP }\end{array}$ & $\begin{array}{l}\text { No. of shoots } \\
\text { on kinetin }\end{array}$ \\
\hline 1 & Medium type (M) & 1 & $29.630 * *$ & 0.019 \\
\hline 2 & Cytokinin (C) & 5 & $94.896 * *$ & $87.519 * *$ \\
\hline 3 & $\mathrm{M} \times \mathrm{C}$ & 5 & $5.363 * *$ & 0.730 \\
\hline 4 & IAA (I) & 2 & 1.394 & $4.338^{*}$ \\
\hline 5 & $\mathrm{C} \times \mathrm{I}$ & 10 & 0.566 & 0.810 \\
\hline 6 & $\mathrm{M} \times \mathrm{I}$ & 2 & 2.532 & $1.094^{*}$ \\
\hline 7 & $\mathrm{M} \times \mathrm{C} \times \mathrm{I}$ & 10 & 0.649 & 0.588 \\
\hline 8 & Error & 180 & 2.094 & 1.074 \\
\hline
\end{tabular}

The number of shoots regenerated from a single explant increased with increases in BAP concentration in the medium. With BAP at $8.0 \mathrm{mg} \cdot \mathrm{L}^{-1}$, the number of shoots regenerated from the single explant decreased, which indicated that BAP had an adverse effect when used at a higher-thanoptimal concentration. Similar proliferation behavior of BAP in banana was observed by Vuylsteke (1989) and Arinaitwe et al. (2000) during multiplication of 'Nzizi', 'Kibuzi', and 'Ndiziwemiti', respectively. During in vitro multiplication of 'Ndiziwemiti' and 'Kibuzi', the rate of multiplication increased with increase in BAP concentration up to 16 $\mu_{\mathrm{M}}\left(3.6 \mathrm{mg} \cdot \mathrm{L}^{-1}\right)$, beyond which it declined suddenly (Arinaitwe et al., 2000). During the present study, the saturation concentration of BAP for 'Basrai' was $6.0 \mathrm{mg} \cdot \mathrm{L}^{-1}$, beyond which multiplication rate started to decline (Table 1). Higher concentrations of BAP and kinetin beyond optimum levels were also reported to cause necrosis and reduction in shoot formation during in vitro multiplication of 'Nendran' (Madhulatha et al., 2004).

It was observed that, in the presence of BAP, the physical state of the medium (solid/ liquid) also affected shoot multiplication significantly (Table 2). A higher multiplication rate was observed in liquid medium where cultures were continuously shaken to ensure a uniform distribution of nutrients, which may be the reason for the increased proliferation rate. On the other hand, in the solid medium, a lack of uniform distribution of nutrients and accumulation of phenolics in close proximity of the explant may have resulted this differential response. These results are in agreement with the findings of Bhagyalakshmi and Singh (1995) for 'Cavandishi', 'Bluggoe', and 'Silk' when multiplied on MS medium containing $2.0 \mathrm{mg} \cdot \mathrm{L}^{-1}$ $(8.9 \mu \mathrm{M})$ BAP and $1.8 \mu \mathrm{mg} \cdot \mathrm{L}^{-1}(0.89 \mu \mathrm{M})$ indole 3-butyric acid (IBA) in liquid and agar-gelled media.

In our experiments, it was observed that IAA auxin did not affect shoot proliferation. Interaction of IAA with cytokinins and medium phase were also nonsignificant (Table 2). Plants regenerated roots on medium without or at lower concentrations ( 1 or $\left.2 \mathrm{mg} \cdot \mathrm{L}^{-1}\right)$ of BAP (data not shown). When IAA at 1 or 2 $\mathrm{mg} \cdot \mathrm{L}^{-1}$ was added to the medium containing BAP, shoot length increased (data not shown) while number of shoots regenerated from a single explant remained the same. When 1 or $2 \mathrm{mg} \cdot \mathrm{L}^{-1}$ IAA was applied in combination with $8.0 \mathrm{mg} \cdot \mathrm{L}^{-1} \mathrm{BAP}$, callus-like swelling was observed at the base of explants but resulted in no enhancements in shoot proliferation. The presence of auxins in the medium influenced the cell enlargement, root initiation, and suppression of lateral bud formation (Jarret et al., 1985; Madhulatha et al., 2004; Zaffari et al., 2000). The same response was observed during the present study.

When cultures were shifted to media with various concentrations of kinetin, the number of shoots increased with increase in kinetin concentration up to a certain level, beyond which number of multiple shoots decreased, indicating a saturation concentration (Table 1). On control medium, the average numbers of shoots were $1.3 \pm 0.10$ and 1.3 , which increased to 4.7 and 4.4 shoots per explant when the medium was supplemented with $6.0 \mathrm{mg} \cdot \mathrm{L}^{-1}$ kinetin in liquid and solid phase, respectively. The increase in kinetin concentration increased the proliferation rate significantly. At lower concentrations of kinetin, the buds present at base of leaves grew and no adventitious shoots were observed. With the increase in kinetin concentration, an apical dominance effect of cytokinin was observed, and adventitious shoots also appeared around the rhizome of the main explant. The same pattern of shoot multiplication was observed with increases in kinetin concentration as with BAP. The number of shoots was 5.4 on $4.0 \mathrm{mg} \cdot \mathrm{L}^{-1} \mathrm{BAP}$ while kinetin produced 4.3 shoots on the same concentration, which was $20 \%$ lower than the number of shoots on 
BAP-containing medium. These results are in accordance with findings of Arinaitwe et al. (2000) during the multiplication of the 'Ndiziwemiti'. They were able to achieve a maximum of 3.8 shoots/explant on $24.8 \mu \mathrm{M}$ (5.3 $\left.\mathrm{mg} \cdot \mathrm{L}^{-1}\right)$ kinetin; this decreased to 2.1 shoots per explant when kinetin was increased to $28.8 \mu \mathrm{M}\left(6.25 \mathrm{mg} \cdot \mathrm{L}^{-1}\right)$, which showed a saturation effect of kinetin. From our results, it was also observed that the number of multiple shoots on liquid medium was higher than on solid medium, but the difference was statistically significant only with BAP-containing media (Table 2). When means were compared by least-significant difference (LSD), the shoot numbers on media having $4.0,6.0$, and $8.0 \mathrm{mg} \cdot \mathrm{L}^{-1}$ kinetin did not vary significantly except for 8.0 $\mathrm{mg} \cdot \mathrm{L}^{-1}$ kinetin in liquid medium (Table 1 ). Madhulatha et al. (2004) used BAP and kinetin in combination and found that, beyond $200 \mathrm{mg} \cdot \mathrm{L}^{-1}$, the number of shoots per explant fell to 5.05 from 14.12 , indicating an adverse effect of cytokinins on shoot proliferation of 'Nendran' during the study of effect of liquid pulse treatment on shoot multiplication.
On the basis of our results, it was concluded that BAP performed better than kinetin for in vitro multiplication of 'Basrai'. Variation in the activity of different cytokinins can be explained by differences in the uptake rates reported in different genomes (Blakesly, 1991), varied translocation rates to meristematic regions, and metabolic processes in which cytokinin may be degraded or conjugated with sugars or amino acids to form biologically inert compounds as reported by Kaminek (1992).

\section{Literature Cited}

Arinaitwe, G., P.R. Rubaihayo, and M.J.S Magambo. 2000. Proliferation rate effects of cytokinins on banana (Musa spp.) cultivars. Scientia Hort. 86:13-21.

Bhagyalakshmi, N.S. and N.S. Singh. 1995. Role of liquid versus agar-gelled media in mass propagation and ex vitro survival in bananas. Plant Cell. Tiss. Org. Cult. 41:71-73.

Blakesly, D. 1991. Uptake and metabolism of 6benzyladenine in shoot cultures of Musa and Rhododendron. Plant Cell. Tiss. Org. Cult. 25:69-74.

GOP. 2006. Banana (Table 47), p 91. Agricultural statistics of Pakistan 2004-2005. Government of Pakistan, Ministry of Food, Agriculture, \& Livestock, Islamabad, Pakistan.

Jarret, R.L., W. Rodriguez, and R. Fernandez. 1985. Evaluation, tissue culture propagation and dissemination of 'Saba' and 'Palpita' plantations in Costa Rica. Scientia Hort. 25:137-147.

Kaminek, M. 1992. Progress in cytokinin research. Trends Biotechnol. 10:159-162.

Madhulatha, P., M. Anbalagan, S. Jayachandran, and N. Sakthivel. 2004. Influence of liquid pulse treatment with growth regulators on in vitro propagation of banana (Musa spp. AAA). Plant Cell. Tiss. Org. Cult. 76:189-192.

Murashige, T. and F. Skoog. 1962. A revised medium for rapid growth and bioassays with tobacco tissue cultures. Physiol. Plant. 15:473497.

Soomro, M.H., S. Khalid, and M. Aslam. 1992. Outbreak of banana bunchy top virus in Sindh, Pakistan. FAO Plant Protection Bull. 40:95-99.

Vuylsteke, D. 1989. Shoot-tip culture for the propagation, conservation and exchange of Musa germplasm. Practical manuals for handling crop germplasm in vitro 2. International Board of Plant Genetic Resources, Rome, Italy, $56 \mathrm{pp}$.

Zaffari, G.R., G.B. Kerbauy, J.E. Kraus, and E.C. Romano. 2000. Hormonal and histological studies related to in vitro banana bud formation. Plant Cell. Tiss. Org. Cult. 63:187-192. 